\title{
Types of Conjugal Interactions and Conjugal Conflict: A Longitudinal Assessment
}

\author{
Eric Widmer, Jean Kellerhals and René Levy
}

This paper deals with the diversity of contemporary family interactions and its consequences with regard to conjugal conflict, on the basis of a large and longitudinal survey on married and unmarried couples, conducted in Switzerland at the turn of the millennium. Using cluster analysis, we first define five types of conjugal interaction (Bastion, Companionship, Cocoon, Association, and Parallel). The types of conjugal interactions characterized by a strong emphasis on partners' autonomy trigger in the short term a significantly larger number of problems and conflicts. Conjugal dissatisfaction and separation are more likely in Associative and Parallel types of functioning. Overall, results show that conjugal modernity expresses itself through various models, each with specific functional consequences.

Researchers in the field of family interactions have been especially concerned with the problems or crises that contemporary couples face. Nevertheless, there are very few studies worldwide that systematically relate these problems to the logic underpinning conjugal relationships. Some psychological approaches have paved the way (Reiss, 1971, 1981; Kantor and Lehr, 1975; Olson and McCubbin, 1983); however, they are mostly based on the observation of clinical populations. As a consequence, they relegate to the background the sociological dimensions of conjugal functioning and conjugal conflict. From the point of view of family sociology, two current issues are particularly crucial. The first issue concerns the pluralization of family life since the 1960s, and the second issue addresses the potential functional consequences of this diversity. In opposition to broad dichotomies between traditional and modern or postmodern families, we hypothesize that conjugal modernity is characterized by a limited set of alternatives rather than by a single model and that each of these alternatives has a strong impact on the likelihood of conjugal conflict.
This article tests these two hypotheses, using a comprehensive and longitudinal dataset of Swiss couples (Widmer et al., 2003).

\section{Reconsidering Family Diversity}

Most scholars have addressed the issue of family diversity by focusing on household composition: great changes have been acknowledged in the distribution of household types since the sixties, from nuclear family households to single parent households and recomposed households, etc. However, focusing on family structures is but one approach to family diversity, as structural changes are likely to be the expressions of more fundamental trends in intimate interactions within families. Indeed, some scholars suggest that conjugality or, more broadly, intimacy, follows an emerging global logic, captured by the concept of 'pure relationships'. Pure relationships are defined by a focus on the exploration of the self, the centrality of negotiation processes, symmetry in 
power relationships, and a weakening of external constraints (for instance, see Giddens, 1991, 1992). The hypothesis of the spread of pure relationships as a homogenous and dominant logic in contemporary family life closely matches the hypothesis of the development of the "modern" family, described as early as 1945 by Burgess et al. (1960) in their ideal-type of the companionship family. In these perspectives, cohabitation, divorce, and family recomposition are consequences of a much deeper and global trend towards family individualism and life course individualization.

Other scholars, however, have underlined the distinctiveness of various logics underlying conjugal interactions, and the impact that social class, position in the life course, and birth cohorts have on them (for a review, see Widmer et al., 2003). Therefore, the definition of the modern family as a homogeneous entity has been questioned. As a consequence, the distinction between the Institution and Companionship family types proposed by Burgess et al. (1960) has largely given way to analyses centered on the diversity of contemporary family interactions and their classification into various types (Farber, 1962; Bernard, 1964; Kantor and Lehr, 1975; Donati, 1985; Roussel, 1985).

In this regard, sociological research on conjugal functioning has underlined the import of eight dimensions (Widmer et al., 2003; Kellerhals et al., 2004):

- The degree of fusion, which designates the extent to which individual resources (time, money, ideas, feelings) are pooled by spouses or partners.

- The degree of openness, which designates the extent of informational and relational exchanges intervening between the family group and its close environment.

- The main focus, either external or internal, of priority objectives assigned to the couple or the family. Are they internal goals or external goals?

- The degree of gendering (sex typing) of conjugal instrumental roles, which designates the extent of gendered division of household labor and professional activities.

- The degree of gendering of relational roles (such as providing information, goals selection, support, emotional management).

- The degree of gendering of decisional power.

- The normative strength of sex-specific master statuses in couples. This dimension captures the differential investment of men and women in the domestic sphere, which is not only a question of time of presence, but is also connected with the sacrifices that one can or is willing to make for it. It is based on the hypothesis, proposed by Krüger and Levy (2001), that there is still a priority sphere of investment for each gender, the domestic sphere for women and the public sphere for men, which subordinates the investments that either gender can put in the other sphere.

- The degree of routinization, i.e. the extent to which couples follow a fixed set of norms concerning family timetables, eating habits, and territorial allocations. The first three dimensions refer to the concept of cohesion, whereas the next three dimensions refer to the concept of regulation.

To our knowledge, most family typologies have focused on small subsets of those dimensions (usually two dimensions per typology), which is a shortcoming of the typological approach of family interactions (for a critical assessment, see Kellerhals et al., 1993).

\section{Diverse Consequences of Conjugal Interaction Types}

A second crucial issue in family sociology deals with the consequences of conjugal interaction types. From a functional point of view, contemporary families are characterized by various tensions. The first tension opposes the fusional ideals of conjugal happiness, in which 'sharing' is considered a key to happiness, to the rather individualistic ideas of the self, in which clearly establishing personal rights and autonomy is considered as a sign of psychological maturity and evidence of relationship success (Mansfield and Collard, 1988). Another tension is constituted by an obvious gap between, on the one hand, the representations and ideals that insist on equality and the altruistic negotiation of power, and on the other hand, the persistence of un-egalitarian practices, be it in matters of the division of household labor or of socialization roles (Finch and Morgan, 1991).

If, indeed, research has shed light on the structural differences among various types of conjugal interactions, their functional consequences are still widely unknown. The properties of conjugal types of interactions may be examined from two perspectives. First, they can be dealt with in purely quantitative terms: are these types of conjugal interactions associated more or less with problems? An alternative hypothesis states that every type presents a particular profile of problems: for example, one type might encourage communication, while another one might promote speed of decision. In 
this second perspective, conjugal problems could be similar in intensity but of a distinct nature depending on the type of interactions.

This article deals with the following issues. First, is conjugal functioning today largely characterized by a single model or rather by distinct models of interactions? In other words, can conjugal interactions be summarized by a single dominant model corresponding basically to pure relationships? Or, on the contrary, do we still face distinct models of conjugal functioning? Second, do these models lead to specific problems and conflicts, and to uneven levels of conjugal satisfaction?

\section{Data}

In order to assess the logics underlying conjugal functioning and their impact on conjugal conflict, we have made use of the study 'Social Stratification, Cohesion and Conflict in Contemporary Families' (Widmer et al., 2003), a large and two-fold survey of 1,534 couples living in Switzerland conducted by the University of Geneva and Lausanne. The first wave was conducted between November 1998 and January 1999. The study's primary goal was to examine how the subjects' social status and position in the life course influenced conjugal interaction and family conflict. The sample for the project was drawn randomly with a non-proportional stratified design based on the three major linguistic areas of Switzerland. To be included in the sample, respondents had to be living together for a least one year; the youngest partner had to be at least 20, and the oldest partner had to be less than 70; they had to be living in Switzerland, but Swiss citizenship was not necessary. We used a computer-assisted telephone survey questionnaire and translated it into the three major idioms of Switzerland (German, French, and Italian). The 1999 sample included 1,534 couples from the three linguistic areas mentioned above. In each couple, both partners (spouses or partners) were interviewed separately for a total number of 3,068 interviews. For most questions, both partners had to provide an answer. Responses were weighted according to the population size of each of the three linguistic regions. Further details on this sample are available elsewhere (Widmer et al., 2003; Widmer et al., 2004a).

Five years later, in 2004, a follow-up of the couples interviewed in 1999 was organized. From the 1,534 couples interviewed in 1999, 90 per cent agreed to a second interview in 1999. For monetary reasons, this second interview was limited to women. It took place in May and June of 2004. One thousand and eighty-nine women from the 1999 sample responded, with a response rate of 71 per cent. Only a subset of questions from 1999 was asked, basically those related to conjugal conflict, and some demographics. In the following analyses, variables measuring conjugal interactions were drawn from the 1999 wave, and variables measuring conjugal conflict were drawn from the 2004 wave.

\section{Measures}

Various measures of conjugal interactions, conjugal conflict, and conjugal quality have been used throughout the study. In this section we provide a brief description of each of these measures. Additional information can be found in other publications (Widmer et al., 2003; Kellerhals et al. 2004; Widmer et al., 2004a; Girardin et al., 2005).

\section{Conjugal Interactions}

Conjugal interactions were measured in 1999. The eight dimensions of peculiar theoretical importance underlined above were approached by a large number of questionnaire items and gathered in the form of Likert scales, which are listed in the Appendix. In order to measure the degree of fusion, we use nine items with four response categories ranging from 'not at all true' to 'entirely true'. Sample items are: 'you spend most of your evenings with your partner', 'concerning music, books or films, you and your partner have very close tastes', 'all the money that enters the household belongs equally to the two of you', etc. Two separate scales were computed, one for the men and one for the women, as the partners or spouses had to answer separately. They were dichotomized at the median.

The degree of closure is measured by six items, such as 'you go out or see friends several times a week', 'you keep yourself informed daily about economic and political life', or 'you are not very attracted by the mores of other countries', 'you often prefer to stay in family', etc. Every item was recoded so that higher scores indicated a maximum degree of closure. Two scales were again created, one for the women and one for the men, and dichotomized at the median.

The priority objectives assigned to the couple were measured by a set of six statements, and each respondent had to choose the three that best described her or his orientation. Examples included, 'what I am especially looking for in my conjugal life is ... a place of safety, stability', 'a place of tenderness, support' (internal orientation) or, 
alternatively, 'support for my professional life', 'a place of discussion and opening towards the world' (external orientation). Individuals who accepted three assertions marking an internal orientation were said to be internally oriented; answers from both partners were graded separately.

A third set of items concerns the division of household tasks between the partners or spouses. Tasks considered included paperwork (taxes, invoices, accounts), repairs, laundry and ironing, dish washing and cleaning, cooking and shopping, etc. Based on these five items, a scale was built, which was then dichotomized into two situations: massive feminine over-investment (the woman takes responsibility for three-quarters of domestic tasks or more) and all other cases lumped together.

Differentiation of relational roles was approached using a set of seven items, such as 'who brings in most ideas, takes initiatives', 'who offers most support, encourages or comforts others', 'who makes most small sacrifices for the life of the couple/family', etc. To have a synthetic measure of the couple's tendency to differentiate between relational roles, we counted the number of answers 'equally, depends' given by the woman in each couple. The indication ranges from zero, a case in which no role is played equally by both partners, to seven, a case where all the roles were considered undifferentiated. One then distinguished cases giving evidence of a strong differentiation (four to seven roles differentiated, 63 per cent of couples) versus weak differentiation (37 per cent).

Decisional power was measured using seven items, such as 'who decides ... the furniture the apartment', 'chooses the activities of the week-end', 'chooses or changes insurance policies', etc. Couples are considered as strongly gendered if they present an uneven distribution of power in four out of the six considered fields. This is the case of 23 per cent of the couples in the sample, according to the woman's perspective, which was chosen for the study.

To measure the master status differentiation, one item was used that distinguished the cases where only one of the two partners would change his or her commitments in the case of family disturbances (strong differentiation, 50 per cent of cases), from cases where the two partners change their commitment (weak differentiation, 50 per cent of cases). In this case, we focused on the men's answers.

The degree of routinization of the domestic life was measured by a set of six items, such as 'you invite or visit your relatives and your friends on precise days and at precise hours', or 'you see to it that your activities and schedules are regular'. Because of this set of items, the study focused on only one randomly chosen partner per couple, and both sexes answered half the questions. This scale was then recoded at the median into two response categories.

\section{Conjugal Conflict}

All measures of conjugal conflict were drawn from the 2004 wave. For conjugal problems, female partners had to indicate whether or not their couple had experienced a list of nine problems, such as a serious inability to communicate, problems dealing with the partner's personality, sexual problems, infidelity, task sharing problems, etc. Based on previous assessments of the structure of associations existing among the nine items (Girardin et al., 2005), three subscales were computed separately for relational problems, coordination problems, and deviance problems.

Relational problems were measured in 2004 by four items reporting a lack of communication, sexual disagreements, difficulties to do with the partner's personality, and disappointment in love. Respondents had to indicate whether or not they as a couple had experienced any of these problems, which was the case of 30 per cent of couples, with one to four problems cited. A single item measured coordination problems in Wave 2 , which reports whether or not absences of the partner have been a problem, either in the past or present. In 20 per cent of the cases, women reported that they had been a problem.

Violence and addiction problems refer to physical violence, sexual violence, infidelity, and alcohol and drug problems. They were found to be a cluster of variables by correspondence analysis (Girardin et al., 2005). Nine per cent of respondents reported that at least one of these problems had ever existed in the couple.

Conjugal disagreements were measured in 2004 using two indicators describing the frequency of open conjugal disagreements and the severity of those disagreements. Thirty-four per cent of women reported that important disagreements occurred at least once a week, and 15 per cent considered those conflicts to be very serious.

Poor coping strategies were measured by a single item, asking respondents to report whether or not conjugal problems were solved properly or not. Seven per cent reported that they were not solved adequately.

Conjugal dissatisfaction was measured by a single question: 'Overall, how would you rate your couple? Are you going along ...?'. Responses ranged from 'very well' to 'really bad'. Fifty per cent of women did not choose the response "very well". 
Conjugal instability was measured by asking respondents whether or not they had already thought about separating, which was the case in 26 per cent of women.

Conjugal separation was measured by asking respondents if they had separated from and/or divorced their partner or husband since the previous interview. Seven per cent of them have done so.

\section{Results}

Types of conjugal interactions were defined first. Then, we tested whether or not these types trigger specific conjugal problems, disagreements and ability of coping. Finally, we measured the extent to which conjugal types precipitated unequal levels of conjugal satisfaction and conjugal separation.

\section{Types of Conjugal Interactions}

To determine the number of types of conjugal interactions, we computed a sequence of hierarchical clusters (based upon Ward's method of clustering). We examined solutions from three to seven clusters and found the solution with five to strike a good balance between the within-cluster homogeneity, clarity, and parsimony. The results of this analysis are presented in Table 1.
Bastion couples are characterized by a strong tendency to closure, fusion, and gender inequality. In these couples, contact with the external world is not valued much. Quite the contrary, some mistrust exists toward external actors, whereas internal relationships are valued and sought. The family as a group comes first, compared with individual interests or orientations. This rather close and warm world is sustained by a traditional division of labor between genders, in relation with rigid norms. These are couples in which each spouse knows quite well what his or her contributions are supposed to be, depending on gender roles. This strong inequality has also an effect on orientation, women being much more internally oriented in this type. Sixteen per cent of couples show this type of interaction. This is the type closest to the traditional family form as described by Burgess et al. (1960) with the Institution family type.

Associative couples are the opposite of the previous type on all accounts. They are low on both fusion and closure: Associative couples are open and autonomous. They also present an egalitarian power and role distribution. On this basis, one can state that the central values structuring this kind of functioning are at the same time the quest for personal authenticity and the negotiation of individual rights. Associative couples represent 29 per cent of the sample. This is the type which most closely

Table 1 Results of cluster analysis based on responses from both partners (percentages, $n=1534$ )

Parallel Companionship Bastion Cocoon Associative $\begin{gathered}\text { Average } \\ \text { percentages } \\ \text { (whole sample) }\end{gathered}$

\begin{tabular}{|c|c|c|c|c|c|c|c|}
\hline Size of cluster (\% total) & 17 & 24 & 16 & 15 & 29 & & \\
\hline \multicolumn{8}{|l|}{ Cohesion } \\
\hline Fusion (women) & 17 & 57 & 92 & 67 & 05 & 42 & $0.66^{\star *}$ \\
\hline Fusion (men) & 24 & 91 & 74 & 83 & 13 & 53 & $0.68^{\star *}$ \\
\hline Closure (women) & 81 & 19 & 58 & 65 & 09 & 40 & $0.58^{\star *}$ \\
\hline Closure (men) & 68 & 20 & 28 & 56 & 20 & 35 & $0.41^{\star *}$ \\
\hline $\begin{array}{l}\text { Internal orientation } \\
\text { (women) }\end{array}$ & 60 & 16 & 42 & 72 & 11 & 34 & $0.50^{\star *}$ \\
\hline $\begin{array}{l}\text { Internal orientation } \\
\quad(\text { men })\end{array}$ & 16 & 16 & 09 & 95 & 19 & 27 & $0.63^{\star *}$ \\
\hline \multicolumn{8}{|l|}{ Regulation } \\
\hline $\begin{array}{l}\text { Strong differentiation } \\
\text { of functional roles }\end{array}$ & 60 & 49 & 79 & 48 & 53 & 57 & $0.21^{\star *}$ \\
\hline $\begin{array}{l}\text { Strong differentiation } \\
\text { of relational roles }\end{array}$ & 74 & 38 & 91 & 70 & 60 & 63 & $0.36^{\star *}$ \\
\hline $\begin{array}{l}\text { Strong differentiation } \\
\text { of decisional power }\end{array}$ & 31 & 13 & 23 & 18 & 24 & 22 & $0.15^{\star *}$ \\
\hline Strong master status & 56 & 24 & 74 & 42 & 60 & 50 & $0.34^{\star *}$ \\
\hline Strong routinization & 45 & 34 & 76 & 56 & 27 & 44 & $0.35^{\star *}$ \\
\hline
\end{tabular}


follows the logic of pure relationships (Giddens, 1991, 1992) with its emphasis on autonomy, negotiation, and exploration of the self using family relationships.

Companionship couples are characterized by a strong tendency toward fusion, unlike Associative couples. At the same time, they are very open. Their level of sexual inequality is close to the mean. The dominant value in this type of interaction is the use of contextual resources in order to reinforce internal solidarity and communication. Companionship couples represent 24 per cent of the sample, and closely resemble the homonymous type of Burgess et al. (1960).

High levels of fusion and closeness characterize couples of the Cocoon type. They do not, unlike Bastion couples, present a high-level gender division of domestic and relational roles. Both partners show a strong tendency to emphasize internal goals, in contrast to Bastion couples, in which only women show such a tendency. Their functioning is at the same time warm, closed, and relatively free of gender inequalities. They represent 15 per cent of the sample.

Parallel couples are characterized by a strong differentiation of domestic and relational roles between spouses or partners. They are strong on female expressiveness and on male instrumentality. Parallel couples have comparatively low scores of fusion and high scores of closure. They feel threatened by the external world (of the family) without, however, investing in the internal relationships. The idea of separate worlds for spouses or partners constitutes the core of this functioning. This type includes 17 per cent of our couples. Parallel and Cocoon type couples are not as clearly definable in comparison to Institution and Companionship families (Burgess et al., 1960), or pure relationships. They are mixes of various traits that former research often considers contradictory.

The five types of conjugal interactions largely use the space defined by the eight dimensions of cohesion and regulation. It is also worth underlining that these types of conjugal interactions are associated with social status of spouses (Widmer et al., 2004a): the Bastion, Parallel, and Cocoon types are much more frequent in couples of low social status. The frequency of the Associative type of conjugal interactions is significantly greater in couples with a high social status. It is also notable that these types depend to a significant extent on the family stage to which each couple belongs (couple without children, couple with youngest child as a preschooler, etc.), and other related dimensions, such as the duration of the partnership and the age of partners (for detailed assessments, see Kellerhals et al., 2004; Widmer et al., 2003; Widmer et al., 2004a).

\section{Types of Conjugal Interactions and Conjugal Conflict}

In order to estimate the impact of the types of conjugal interactions net of potential confounding variables, we ran a series of logistic regressions, controlling for family stage (see previous section), level of education, income, homogamy of education, women's professional activity, family structure, etc. (Table 2).

In Table 2, the Companionship type of interaction creates lower conjugal conflict than any other type. Companionship couples (as defined in Wave 1) report tensions and open conflicts significantly less often than others in Wave 2. When open conflicts occur, they are significantly less serious, and reconciliation is easier than for other couples. Companionship couples present conjugal problems of all kinds-much less often than for other couples, in the second wave. In contrast, Parallel and Associative couples score significantly higher on almost all indicators of conflict. Respondents from these couples acknowledge a higher level of tension and more frequent open conflicts than on average. They show higher rates of problems of all kinds. Cocoon and Bastion couples, on the other hand, show a similar response profile to Companionship couples, although they report slightly higher frequencies of problems and open conflicts. Types of conjugal interactions are also associated with unequal abilities to cope with problems: Companionship couples have a much lower score in the coping inefficacy indicator than any other types, especially Parallel and Associative couples.

Conjugal quality, measured five years after conjugal interactions, also depends on types of conjugal interactions, as shown in Table 2. Parallel and Associative couples trigger the highest conjugal dissatisfaction and the most frequent thoughts of separation. Companionship couples have the lowest scores in both measures. Cocoon and Bastion couples rest in-between. Actual separation or divorce, that occurred between Wave 1 and Wave 2, confirm the results of other outcomes. Again, Companionship, and, to a lesser extent, Bastion and Cocoon couples, separated or divorced significantly less than Parallel and Associative couples during the time interval between Wave 1 and Wave 2 .

\section{Discussion}

Results show that an emphasis on autonomy is associated with increased conjugal problems and a deterioration of conjugal satisfaction. A likely explanation for these results points to conjugal individualism. This ideology 


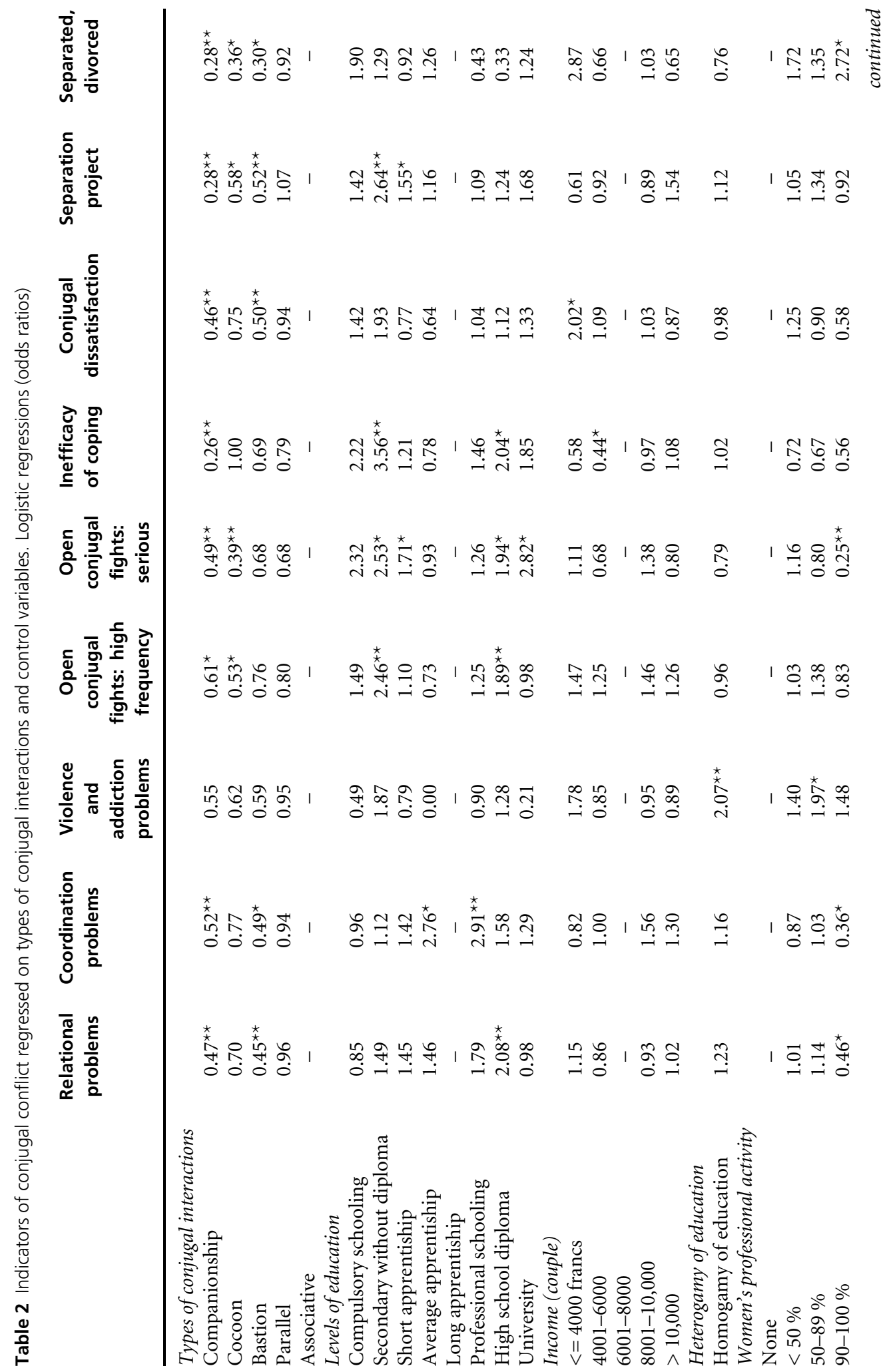




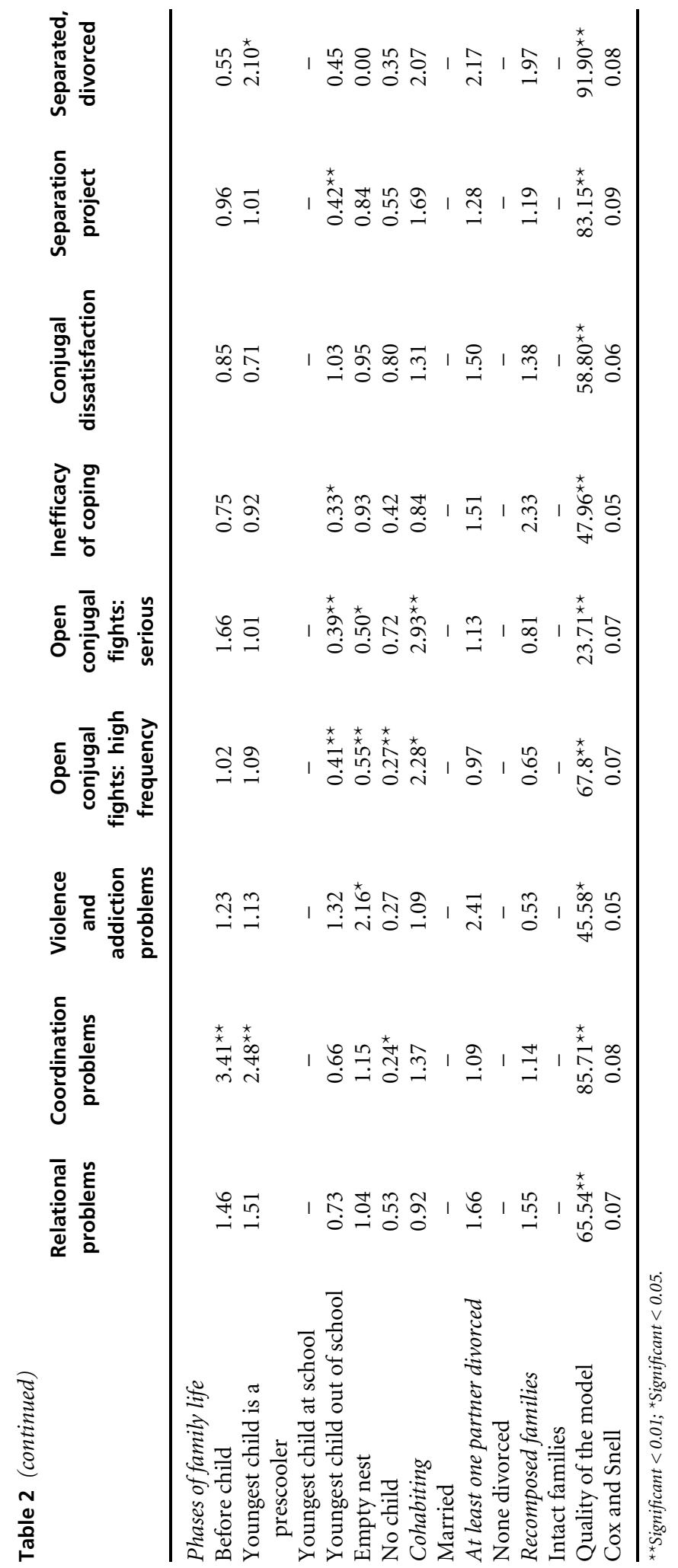


states that the growth of autonomous selves is the only possible justification for conjugal and family life. In its most extreme version, conjugal individualism negates any obligation towards one's spouse or partner except for an open and honest communication (Bellah et al., 1986). Associative couples are those who excel in putting into practice this ideology of individual self-fulfillment through marriage or cohabitation, and they show signs of conjugal conflict much more frequently than other couples do. This result casts doubt on the hypothesis that a broader and more open style of communication could counter-balance the disintegrating effects of individualism on the family (Cheal, 1991). One may wonder whether or not the quest for authenticity and autonomy in intimate relationships (de Singly, 1996), which is so strong in Associative couples, is not actually detrimental to the couple itself. Of course, a fair percentage of Associative couples live up to the expectations associated with this type, which disregards authority claims, gendered inequality, and routinization of family life. Many others, however, do not come close to that ideal and fall back on poor coping strategies which produce chronic conjugal dissatisfaction (Widmer et al., 2003; Kellerhals et al., 2004). The development or enhancement of the 'self' as the main justification of the couple or of the family does not appear to provide enough potential of integration to insure the stability of life in common, because differences among professional and relational agendas of each spouse or partner provide numerous occasions for sentimental estrangement.

A second factor of conjugal conflict in contemporary couples lies in the distance between the ideal of equality and negotiation in modern couples on one side, and the persistence of strong inequalities between men and women in terms of domestic and educational work on the other. The cultural and ideological context is considerably more critical about gender inequalities than it was 20 or 30 years ago. These inequalities are now clearly associated with conjugal problems and a negative estimation of conjugal quality when accompanied by an individualistic orientation, as in the Parallel type of interactions. Thus, the gender divide of roles and power structuring in Parallel couples has its price in terms of conjugal conflict.

Privatization, approached empirically by the closure dimension, is a third risk that threatens contemporary couples characterized by individualism. In another publication, we showed that inclusion in a large and supportive conjugal network shared by the two partners or spouses has a positive impact on conjugal functioning (Widmer et al., 2004b). Note, however, that both gender inequalities and family closure trigger conjugal conflict only when they are associated with conjugal individualism. In other words, they are viable when they are embedded in a conjugal ideology emphasizing the predominance of the family as a whole over the individual.

Overall, the emphasis on autonomy in conjugal relationships makes it difficult for couples to deal with problems adequately. It is as if, in order to sort things out in intimate relationships, it is necessary for both spouses or partners to have a sense that something beyond their individual selves exists. This "couple identity" makes the unavoidable daily inter-individual bargaining and conflicts, inherent to any close relationships, less detrimental. When one is deeply convinced that no matter what happens during every day transactions, the emphasis of both partners is put on the couple rather than on the self, problems are dealt with in a much more open and straightforward way. In that case, one may think that problems are considered with a rather benevolent mind: the attribution of malignant or egoistic intentions to the partner is probably minimal and the definition of the overall situation is kept relatively unchanged as well. Quite to the contrary, when problems arise in couples centered on autonomy, they probably more often cause various doubts about the partner's intentions and dispositions toward ego, which might, through a self-fulfilling prophecy, change the definition of the situation and eventually the situation itself. This is especially the case for Parallel couples, in which strong gender inequalities are associated with a strong emphasis on autonomy.

\section{Acknowledgements}

We gratefully thank Francesco Giudici for his support with statistical analysis. The 1999 study was financed by the Swiss National Science Foundations under grant \# 5004-047772. The follow-up and analysis were financed by the Fonds universitaire Maurice Chalumeau (University of Geneva). PAVIE (Center for life course and life styles studies, Universities of Lausanne and Geneva), and the Swiss National Science Foundation under grant \# 100012-107750/1.

\section{References}

Bellah, R. N., Madsen, R., Sullivan, W., Swidler, A. and Tipton, S. (1986). Habits of the Heart. New York: Harper \& Row. 
Bernard, J. (1964). The Adjustments of Married Mates. In Christensen, H. T. (Ed.), Handbook of Marriage and the Family. Chicago: Rand McNally, pp. 675-739.

Burgess, E. W., Locke, H. J. and Thomes, M. (1960). The Family: From Institution to Companionship. New York: American Book.

Cheal, D. (1991). Family and the State of Theory. New York: Harvester Wheatsheaf.

de Singly, F. (1996). Le couple, le soi et la famille. Paris: Nathan.

Donati, P. (1985). Famiglia e politiche sociali. Milano: Franco Angeli.

Farber, B. (1962). Types of Family Organization. In Rose, A. M. (Ed.), Human Behaviour and Social Processes. London: Routledge and Kegan Paul, pp. 285-306.

Finch, J. and Morgan, D. (1991). Marriage in the 80s: A New Sense of Realism? In Clark, D. (Eds), Marriage, Domestic Life and Social Change. London, New York: Routledge, pp. 52-82.

Giddens, A. (1991). Modernity and Self-Identity: Self and Society in the Late Modern Age. Cambridge: Polity Press.

Giddens, A. (1992). The Transformation of Intimacy: Sexuality, Love, and Eroticism. Cambridge: Polity Press.

Girardin, M., Widmer, E. D., Kellerhals, J. K. and Levy, R. (2005). Intimacy Problems and Conjugal Functioning. European Journal of Sexology, XIV, 51, 25-40.

Kantor, D. and Lehr, W. (1975). Inside the Family: Toward a Theory of Family Process. San Francisco: Jossey-Bass.

Kellerhals, J., Troutot, P.-Y. and Lazega, E. (1993). Microsociologie de la famille. Paris: PUF.

Kellerhals, J., Widmer, E. and Levy, R. (2004). Mesure et démesure du couple. Cohésion, crises et résilience dans la vie des couples. Paris: Payot.

Krüger, H. and Levy, R. (2001). Linking Life Courses, Work and the Family: Theorizing a not so Visible Nexus between Women and Men. Canadian Journal of Sociology, 26, 145-166.

Mansfield, P. and Collard, J. (1988). The Beginning of the Rest of your Life? A Portrait of the Newly-wed Marriage. Basingstoke: Macmillan.

Olson, D. H. and McCubbin, H. I. (1983). FamiliesWhat Makes Them Work. London: Sage.

Reiss, D. (1971). Varieties of Consensual Experience. Family Process, 10, 1-35.

Reiss, D. (1981). The Family's Construction of Reality. Cambridge: Harvard University Press.

Roussel, L. (1985). La famille incertaine. Paris: Odile Jacob.

Widmer, E., Kellerhals, J. and Levy, R. (2003). Couples contemporains: Cohésion, régulation et conflits. Une enquête sociologique. Zürich: Seismo.

Widmer, E. D., Kellerhals, J. and Levy, R. (2004a). Quelle pluralisation des relations familiales? Conflits, types d'interactions conjugales et milieu social. Revue française de Sociologie, 45, 37-67.
Widmer, E. D., Kellerhals J. and Levy, R. (2004b). Types of Conjugal Networks, Conjugal Conflict and Conjugal Quality. European Sociological Review, 20, 63-77.

\section{Authors' Addresses}

Eric Widmer, Université de Lausanne, Centre PAVIE, Bâtiment Provence, 1015 Lausanne, Switzerland. E-mail: eric.widmer@unil.ch

Jean Kellerhals,

René Levy,

Manuscript received: January 2005

\section{Appendix}

\section{Items Operationalizing the Interaction Types}

Fusion-autonomy

Couples today have various ways of life. Tell me first, referring to your couple, if the sentences that I am going to read to you are for you 'true', 'rather true', 'rather wrong' or 'entirely wrong'.

1. You spend most of your evenings with your partner.

2. The religious and political ideas of your partner are close to yours.

3. When you see friends, it is mostly with your partner.

4. All the money that enters the household belongs equally to the two of you.

5. Except for work, you have many activities out of home without your partner.

6. You sacrifice certain personal activities rather than to allow a distance from your spouse to arise.

7. You prefer to give in on an issue rather than to enter into conflict with your partner.

8. In your conjugal relationship, you need a good portion of autonomy.

9. Concerning music, books or films you and your partner have very close tastes.

\section{Closure-openness}

And concerning your PERSONAL HABITS, are the following sentences 'true', 'rather true', 'rather wrong' or 'entirely wrong'?

1. You keep yourself informed daily about the economic and political life.

2. You go out or see friends several times a week.

3. You are not very attracted by the ways and customs of other countries. 
4. You often prefer to stay in family.

5. Your house is very open to friends and kin.

6. You often inquire about the life of the area where you live.

\section{Orientation}

Please choose among the six sentences that follow the three that describe best what you, personally, look for above all in your couple:

1. A place of safety, stability.

2. A place of discussion and opening towards the world.

3. A place to live your faith, your spirituality.

4. A place of tenderness, support.

5. A place of relaxation and entertainment.

6. A support for professional life.

\section{Household tasks}

As regards tasks and the organization of the housekeeping, in comparison with your partner, do you personally do 'everything', 'three quarters', 'half, 'a quarter', or less in the following areas:

1. Meals and shopping.

2. Cleaning, dish washing.

3. Laundry and ironing.

4. Taxes, invoices, accounts.

5. Home and car repairs.

\section{Relational roles}

In daily life, each one has his or her own personality, his or her own role. In your couple, which of you, generally

1. Brings in most ideas, takes initiatives.

2. Offers most support, encourages or comforts others.

3. Makes the atmosphere pleasant, laughs.

4. Settles most quarrels, proposes compromises.

5. Reframes the discussion.

6. Makes most small sacrifices for the life of the couple/family.
7. Has more weight in discussions.

Decisional power

When it is necessary to choose and you and your partner do not agree, who of you two has most weight in the decision? Is it rather you or rather your partner, or both of you equally? For instance:

1. To choose the activities of the weekend.

2. To make or to accept an invitation.

3. To furnish the apartment.

4. To choose the kind of holidays.

5. To make an important purchase.

6. To choose or to change insurances.

Master status

In case of a serious disturbance of your daily life-e.g. moving to another place, serious illness, important problem of relatives-which one of you two would change durably his or her commitments or projects to assure the organization of your common life in this new situation?

1. Above all your partner.

2. Above all yourself.

3. Both of you, it depends.

\section{Routinization}

As regards the organization of your common life, are the following sentences completely true, rather true, rather wrong or completely wrong? In your couple or family:

1. You quickly put everything back to its place.

2. You invite or visit your relatives and your friends on precise days and at precise hours.

3. You do not like to change your family habits.

4. You carefully supervise your expenses, you make your accounts regularly.

5. You see to it that your activities and schedules are regular.

6. You rather often have new friends. 